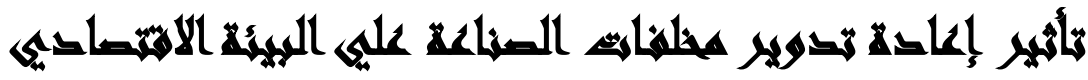

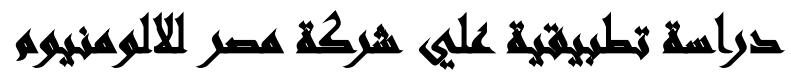

[ri]

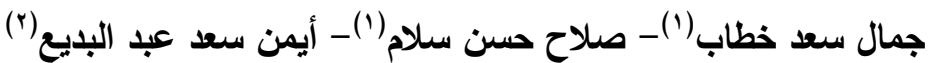

$$
\begin{aligned}
& \text { ( ) كلية التجارة، جامعة عين شمس r (') شركه مصر للالومنيوم. }
\end{aligned}
$$

\section{المستخلس}

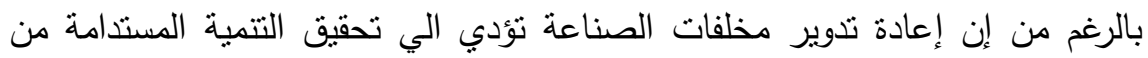

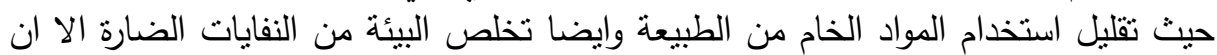
الجدل ما زال قائما بشأن اقتصاديات هذه العملية ـ لذلك هدف البحث الحاثل الحالي الي مقارنة تكلفة الطن الناتج من عمليات تدوير المخلفات الصناعية منها بتكلفة الطن الناتج من المواد الخام بثركة مصر للالومنيوم. استخدم الباحثون المنهج التحليلي الكمى لتحليل بيانات الإنتاج مناج

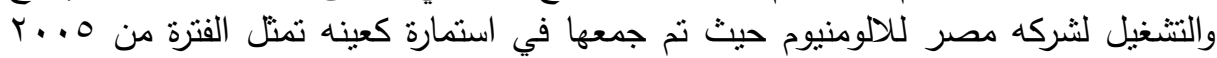
حتى 10 • ب وكانت النتيجة أنه يوجد ارتباط ايجابي قوى بين عمليات اعاده التدوير وكميه

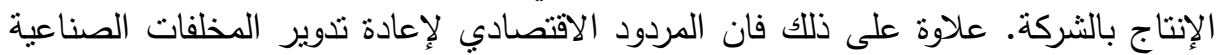

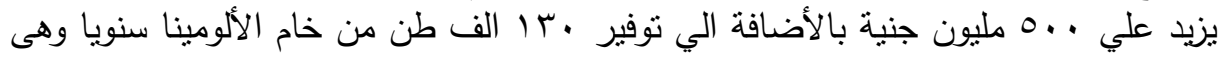

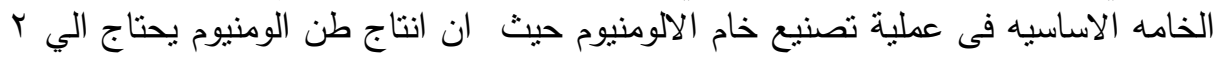

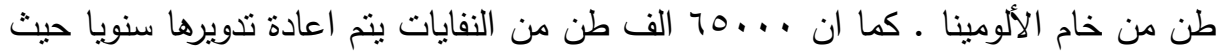
تسهم عملية اعادة التدوير بشكل فعال في التخلص من النفايات الصلبة والتي نتكل خطرا بيئيا متزايدا. ومن ثم تم قبول الفرض الرئيسي للبحث وهو وجود تأثير ايجابي لإعادة تدوير

مخلفات الصناعة على البيئة الاقتصادية بالثركة ومن استقراء نواتج الدراسات السابقة

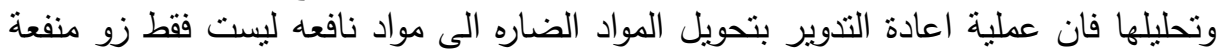
بيئية لكن قد يتحقق من ورائها ايرادا يفوق تكلفة معالجة هذه المخلفات حيث أدى إعتماد شركه

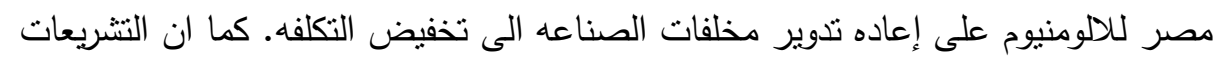
والقوانين الحالية كافيه للقضاء على التلوث بانواعه بشرط تطبيقها بحزم • 


\section{المهابـ}

يتسبب النشاط البشرى فى الحاق الضرر بالبيئه الطبيعيه ويشهـ معظم الناس تلوث البيئه فنصورة مكان مكثوف للنفايات او فى صورة دخان اسود ينبعث من احد المصانع ولكن التلوث قد يكون غير منظور ومن غير رائحه او طعم ومايهمنا فى هذا المقام هو التلوث

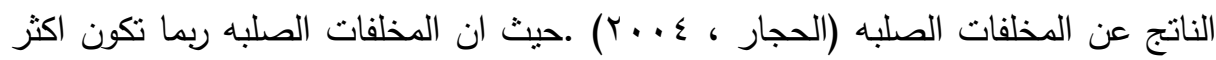
اشكال التلوث ظهورا للعيان ففى كل عام يلقى الناس ببلايين الاطنان من المخلفات الصلبه وتسهم المخلفات الصناعيه بنصيب وافر من هذه المواد المطروحه ـ وتسمى المخلفات الصلبه الصادره عن المنازل والمكاتب والمخازن بالمخلفات البلديه الصلبه وتشمل الورق والبلاستيك والقوارير والعلب والنفايات الغذائيه ونفايات الحدائق ومن المخلفات الاخرى خرد السيارات والمعادن ومخلفات العمليات الزراعيه ومخلفات التعدين (صابر ، 9AV (1) ـ النفايات الصلبه الى تلفظها المنازل والمصانع ربما كانت اكثر مسببات التلوث وضوحا درجت كثيرا من ون المجتمعات على دفن المخلفات فى مناطق واسعه تدعى مدافن النفايات يمثل تداول المخلفات الصلبه مشكلة فى حد ذاته لان معظم طرق التخلص من النفايات تعمل على تدمير البيئه.

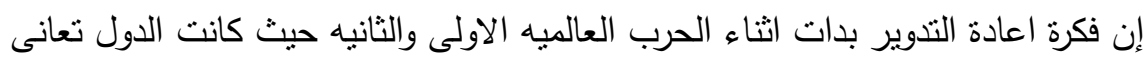

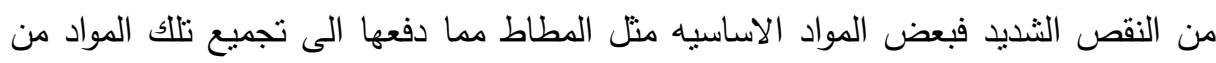
المخلفات لاعادة استخدامها (Schlesinger, 2006). وبعد سنوات أصبحت عملية إعادة التدوير المباشر عن طريق منتجى مواد المخلفات (الخرده)هو الثكل الاساسى لاعادة التصنيع ولكن مع بداية التسعينيات بدأ التركيز على التدوير غيرالمباثر اى تصنيع مواد المخلفات لانتاج منتجات اخرى تعتمد على نفس الماده الخام منل ندوير الزجاج والورق والبلاستيك لنيك والالومنيوم وغيرها من المواد التى يتم الآن اعادة تصنيعها. 


\section{مهرحلة الهميث}

هناك رأيان حول التكلفة الاقتصادية لاعادة التدوير :

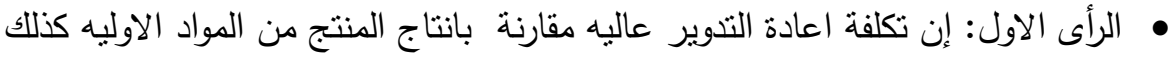
جودة المنتج الناتج من اعادة التدوير اقل جوده (Shapely, 2010).

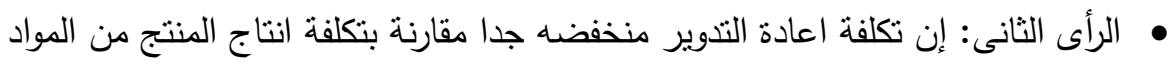

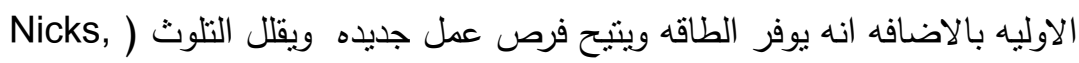

لذا فان الباحثين سيختبروا أى الرأيين أصح وذللك بالتطبيق على شركة مصر للالومنيوم

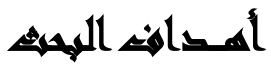

يهدف هذا البحث الي مقارنة تكلفة الطن الناتج من عمليات تدوير المخلفات الصناعية منها بتكلفة الطن الناتج من المواد الخام بشركة مصر للاللومنيوم. لهن

\section{أهميلة المهيه}

تتمنل أهميه الدراسه العلميه فى إظهار أهميه إعاده التذوير وتأثيره على البيئه الاقتصاديه وخصوصاً للشركات الصناعيه.

\section{هرغية المهيه}

يوجد تأثثر ذو دلالة معنوية لإعادة تدوير مخلفات الصناعة على البيئة الإقتصادية

$$
\text { بشركة مصر للالومنيوم. }
$$

\section{الإجراعايت المنهجية وأسوائ الصراسلا}

1. أسلوب التحليل الوصفى الذى يعتدد على وصف البيانات والربط بينها ربطاً منطقياً وإعادة بنائها واستنتاج دلائل جديدة واستخراج المؤشرات. 


$$
\begin{aligned}
& \text { r. أسلوب التحليل الكمى للبيانات ، وذللك باستخدام الطرق الإحصائية والأساليب الاقتصادية }
\end{aligned}
$$

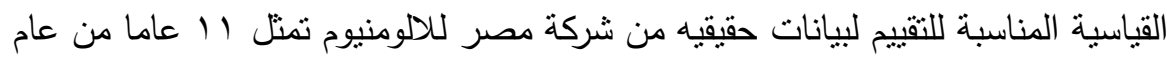

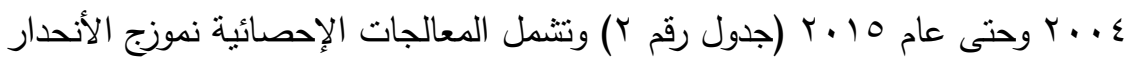

$$
\begin{aligned}
& \text { الخطي البسيط لقياس مدي اعتماد بعض المتغير اجنيرات علي بعضها البعض كما تم حساب } \\
& \text { معامل الارتباط. }
\end{aligned}
$$

\section{هجالاهي التواسم}

المجال المكاني: داخل شركة مصر للالومنيوم كاحد قلاع الصناعه فى مصر

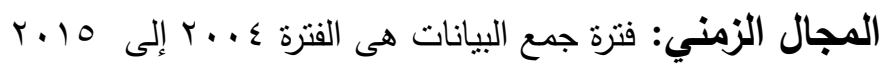

\section{التراساهي الساريش}

عنوان الدراسة: نصف الماء المعبأ ياتي من اعادة التدوير ولكن تكلقك اكثر.

التكلفه الحقيقيه لاعادة التدوير

$$
\text { • مؤلف الدراسة: Shapely }
$$

$$
\text { • عنه الدراسه: } 2010
$$

• أهم محتويات وأهداف الدراسه: تكلفة اعادة التدوير الحقيقية

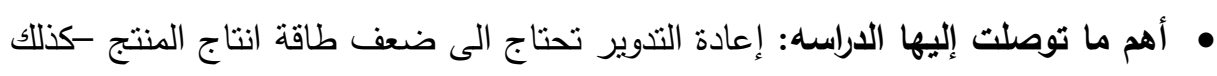
سيارات خاصه لنقل المخلفات كذلك ان اعادة التدوير لن تحمى الاشجار من الاستخدام

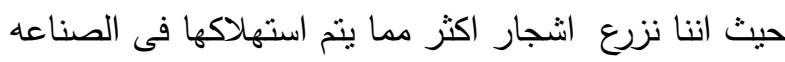
• تعليق الباحث: هذه الدراسه تتعارض مع فرض الباحث عنوان الدراسه: النفايات

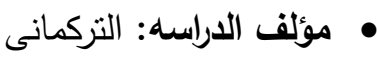


جمال سعد خطاب وآخرون

• أهم محتويات وأهداف الاراسه: كيفيه الاستفاده من النفايات اقتصادي • أهم ما توصلت إليها الدراسه: تدوير المخلفات سيؤدى الى تقليل الاعتماد على الموارد

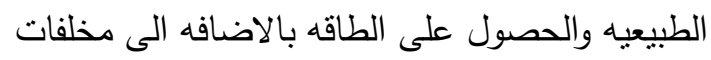
• تعليق الباحثين: هذه الدراسه تتوافق مع فرض البحث عنوان الاراسه: سلبيات وايجابيات اعادة تدوير المخلفات • مؤلف الدراسه: NICKS • سنه الدراسه:

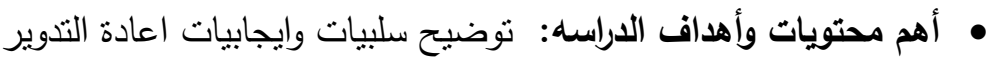
• أهم ما توصلت إليها الدراسه: ان ايجابيات اعادة التدوير تتلخص فى (حماية للبيئهُتوفر الطاقه-منتجات اعادة التدوير رخيصة الثن - يقلل التلوث)، سلبيات اعادة التدوير: منتجات اعادة التدوير جودتها اقل ممواقع اعادة التدوير غير المحكمه قد تؤدى الى لى لئه اضرار بيئيه

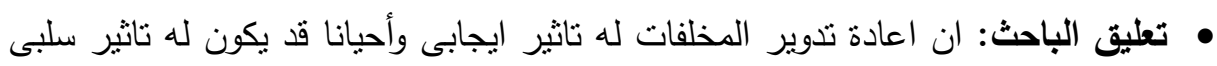

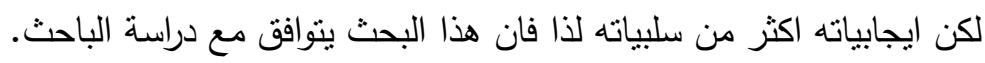

\section{الإلطار اللزظلريه}

المفاهيم المتصله بعطلية إعادة تدوير مخلفات الصناعه: • مفهوم استرداد المواد: مصطلح يعبر عن الانتفاع بمكونات النفايات الصناعيه كمواد ثنانويه. • مفهوم إعادة الاستخدام: مفهوم يعبر عن إعادة إدخال المواد المسترده للاستخدامات

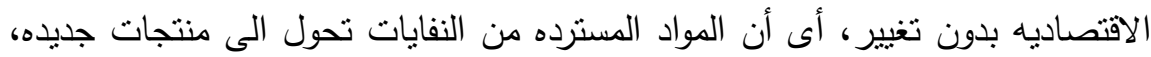

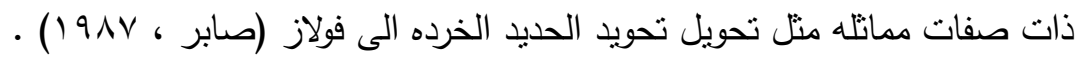




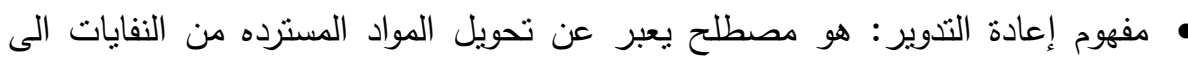
منتجات جديده بتغيير طبيعتها قبل اعادة استخدامها مثل مفهوم تحويل النفايات الصناعيه العضويه الى سماد عضوى صناعى بعد كمرها (صابر ، 9 (19V) )

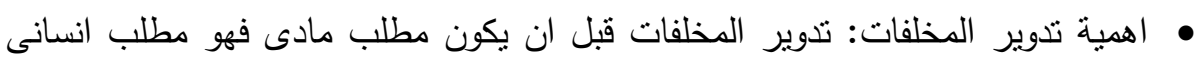

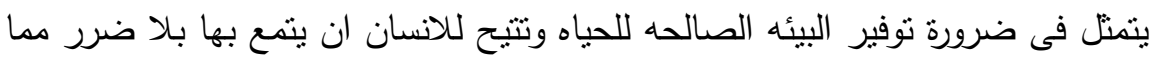

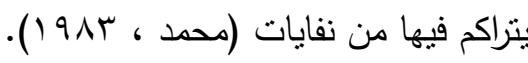
لذا يمكن القول ان اعادة تدوير المخلفات تعتبر عمليه صناعيه مدخلاتها عناصر نلوث البيئه" المخلفات "ومخرجاتها منتجات جديده تعتبر المواد الخام الاساسيه لها هى عناصر الهر

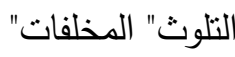

\section{عمليات إعادة التدوير : - ت}

إعادة تدوير الورق: تعتبر عملية اقتصادية من الدرجة الأولى وذلك طبقا لإحصائية حماية البيئة بالولايات المتحدة فان إنتاج طن واحد من الورق\% من مخلفات ورقيه سوف يوفر

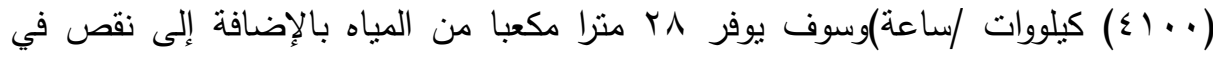

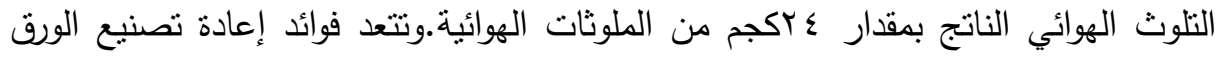

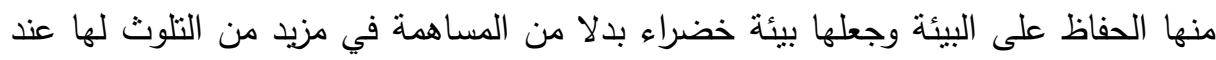

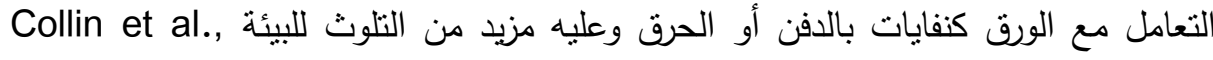

إعادة تدوير البلاستيك: ينقسم البلاستيك إلى أنواع عديد يمكن اختصارها في نوعين رئيسيين

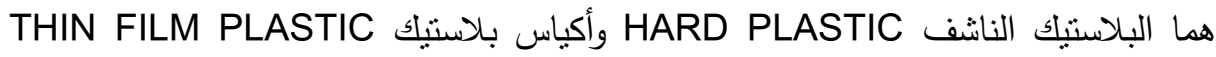
ويتم قبل إعادة التدوير غسل البلاستيك بمادة الصودا الكاوية المضاف إليها الماء الساخن

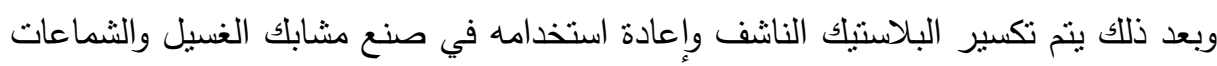
وخراطيم الكهرباء البلاسنيكية إما بلاستيك الأكياس فيتم إعادة بلورته في ماكينات البلورة.

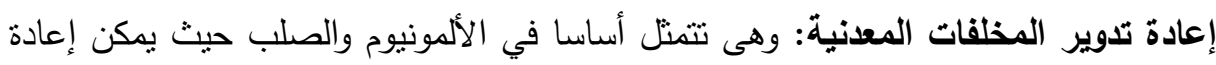

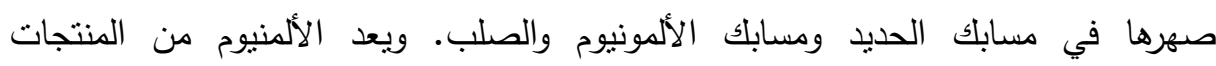


الاستهلاكية الأكثر معاد تدويرها في العالم. كل عام، صناعة الألمنيوم تدفع أكثر من .. A

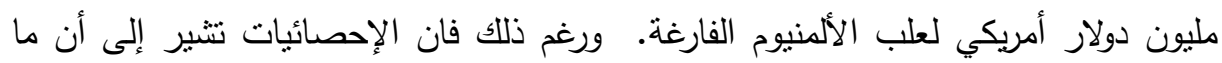
يعادل • ؛ \% من الألمونيوم المنتج في الولايات المتحدة منذ عام . .9 19 لم ينم إعادة تدويره

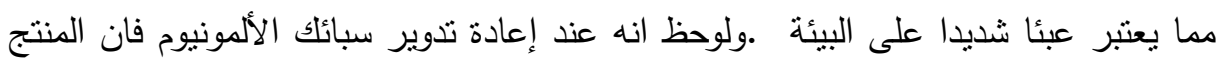

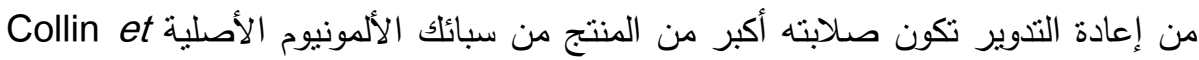
. (al., 2010)

ويمكن اعتباره من المخلفات التي يمكن إعادة تدويرها . .. \% ولعدد لا نهائي من

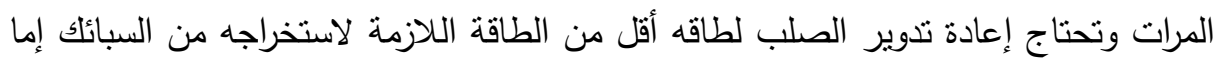
تكاليف إعادة تدوير الألمونيوم فإنها تمتل •r\% فقط من تكاليف تصنيعه وتحتاج عملية إعادة تدوير الألمونيوم إلى ه\% فقط من الطاقة اللازمة ورغم الصعوبات التي نواجه إعادة تدوير مخلفات الألمونيوم هي نركيز بعض الثوائب منل النيكل والنحاس والزناستك والسيلكون والمنجنيز والتي تحتاج لكثير من الطاقة ولكن لحسن الحظ فقد نطورت طرق التنقية في العشر

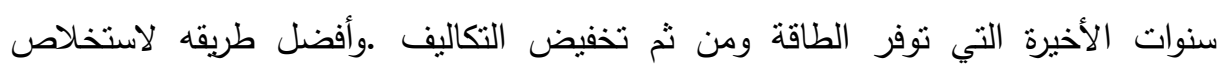

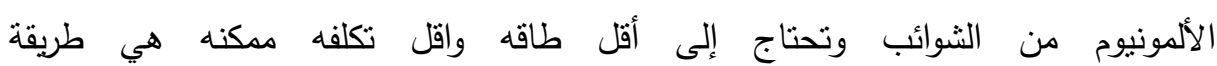
hydrometallurgical method

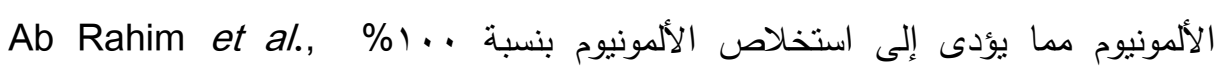

إعادة تدوير الزجاج: صناعة الزجاج من الرمال تعتبر من الصناعات المستهكة للطاقة بشكل

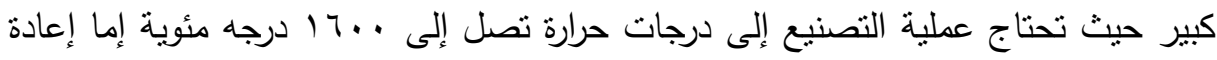

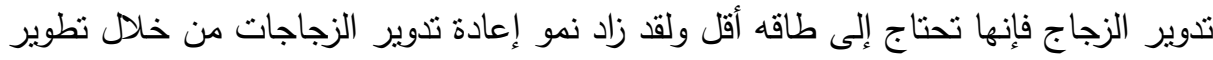
تكنولوجيات التجهيز التي تزيد من درجات نقاء المنتج وتقليل التكاليف التتغيلية . (Worthington et al., 2014) 
إعادة تدوير المخلفات الحيوية: تتمثل المخلفات الحيوية في بقايا الأطعمة ونواتج تقليم الأشجار والحقول ويعاد تدوير هذه المخلفات في وحدات تصنيع السماد العضوي لإنتاج مواد ذات قيمة سمادية عالية ويتم التخلص من جميع المخلفات بعدة طرق مثل -إعادة التدوير -

$$
\text { الحرق - الدفن - الحرق بهدف إنتاج الطاقة (تكنولوجيا الاسنرجاع الحراري). }
$$

المزايا الاقتصادية لمشروعات إعادة تدوير المخلفات: من المزايا التي تجعل مشروعات إعادة تدوير المخلفات قادرة على توسيع الفرص الاقتصادية للشباب، ما يأتي:

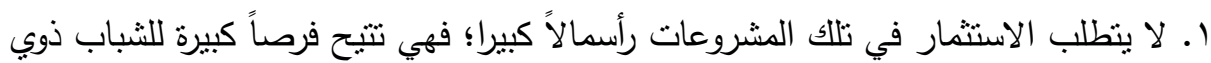
الدخرات الصغيرة للاستثمار فيها. r. إن المورد الأساسي لمشروعات إعادة التدوير هو (القمامة)، ومعروف أن كل الناس

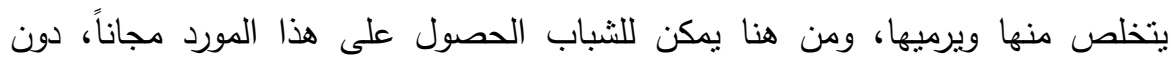

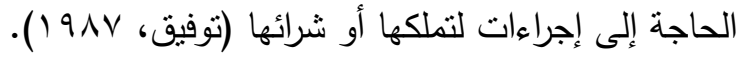

r. تمتاز تقنية إعادة التدوير بسهولة التدريب على استخدامها، ويمكن تعلمها أثناء العمل، كما

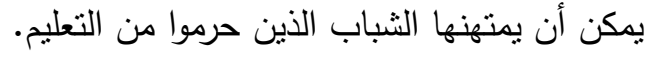
ع. يمكن استخدام آلات محددة ورخيصة الثمن في تقنية إعادة التدوير ، ما يساعد الثباب على الحصول عليها دون تحمل نكاليف كبيرة. ه. وأخيراً، سيتجه الثباب إلى مشروعات إعادة التذوير، عندما يدركون أهميتها لحماية البيئة،

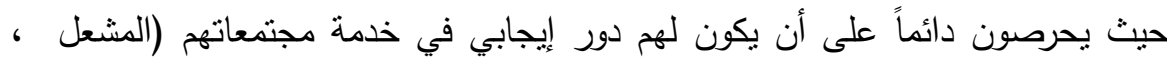

$$
\cdot(r \cdot) T
$$

مزليا عملية إعادة تدوير المخلفات على المستوى القومي: جميع موارد عالمنا

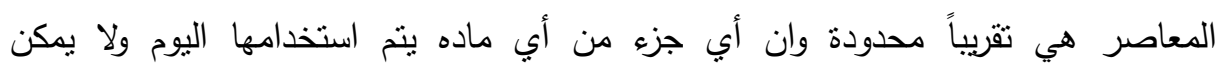

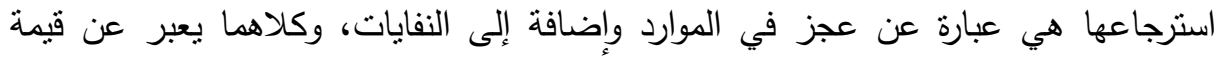
سلبيه يتم سحبها من الرصبد المتبقي للأجيال القادمة فان الجزء من الطاقة الذي استخدم منها

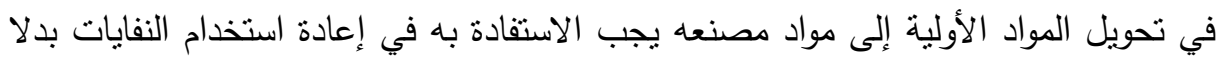


من فقده تماما حيث الطاقة المطلوبة لإعادة تصنيع هذه المواد من النفايات ستكون أقل من تلك المطلوبة لإعادة تصنيعها من المواد الأولية.

كلما زادت طاقة الاقتصاد القومي في مجال إعادة تدوير المخلفات كلما زادت مرونته في

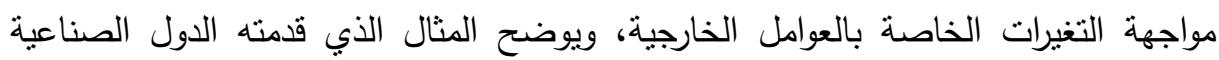
الكبرى التي تمكنت من توفير جزء لا يستهان من المواد البترولية عن طريق برامج دقيقه

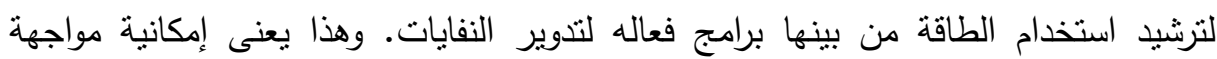

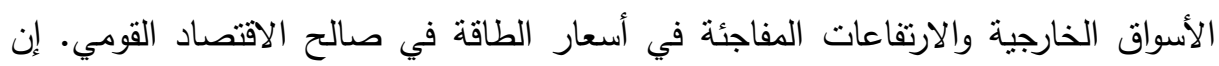

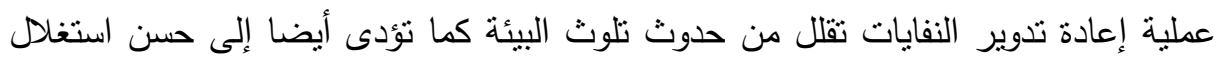
الموارد بإعادة تدويرها.

القواعد المتثددة للتخلص من المخلفات وارتفاع تكاليف التخلص من النفايات أو حيث ضرورة الاهتمام بعملية إعادة تدوير المخلفات كطريقه أفضل للتعامل مع الملوثات، والفائدة المبئية لها هي تخفيض كمية التلوث الناتج واستخدام التلوث كمصدر للطاقة أو كمادة خام ثانوية لإنتاج منتجات جديدة. أن المخلفات الصناعية هي في واقع الأمر مواد ذات نفع كبير وذات عائد مثمر وذات قدره على إيجاد التقدم التكنولوجي من خلال صناعة إعادة التدوير، إذا خططت لها إدارة ناجحة واعية بمطالب التطور ومشاكل التلوث، واضعه نصب أعينها أن الحياة الهادئة للبشر إنش يجب أن تعطى بنفس القدر من العناية كما تحظى به التقنيات الحديثة والعمليات الإنتاجية

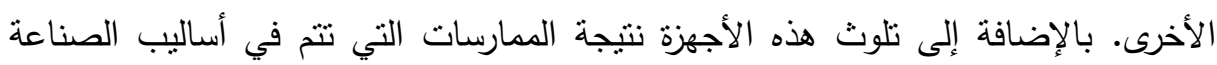

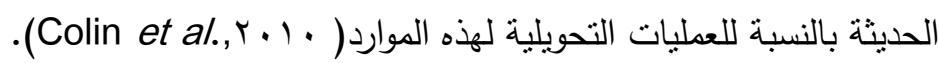

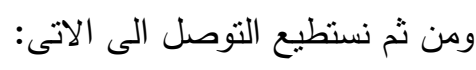

1 علية اعادة التدوبر للمخلفات تقوم على محاولة استخدام تلك المخلفات كمدخلات لعمليات انتاجيه اخرى اى تحويل المواد الضاره الى مواد نافعه ومفيده قد يتحقق من ورائها ايرادا يفوق تكلفة معالجة هذه المخلفات

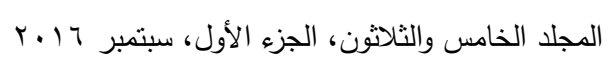


r عمليات اعادة التدوير تقوم على اساس جعل المخلفات مواد نافعه يمكن استخدامها فى انتاج منتجات جديده ويترتب على ذلك تحسين فى البيئه نتيجه الحد من التلوث وانتشار

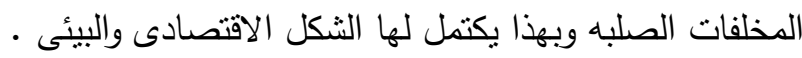
r ان التشريعات والقوانين كافيه لقضاء على التلوث بانواعه بشرط تطبيقها بشده حيث انه لهن

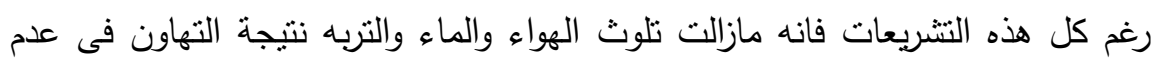

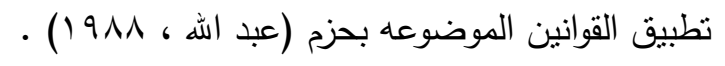
الدراسه التطبيقيه على شركة مصر للالومنيوم: جدول(1): الوفورات الناجمـة عن عمليـة إعـادة تدوير الالومنيوم المعيب ورايش الالومنيوم

\begin{tabular}{|c|c|c|}
\hline & & بشركة مصر للالومنيوم \\
\hline كميه/ القيمه & 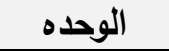 & 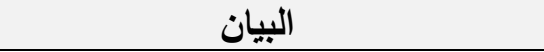 \\
\hline $17 . \Lambda \cdot V$ & مليون جنيه & تكلفه وحده إعاده الصهر \\
\hline TOYY. & ط & كميه المعدن المعاد صهره \\
\hline$\pi r \cdot \leq V$ & طن & كميه المعدن الناتج من إعاده الصهر \\
\hline rVG TVT & مليون جنيه & تكلفه الفقد الناتج عن إعاده الصهر \\
\hline$\cdot . \cdot 1 r$ & مليون جنيه & تكلفه الطن مصهور \\
\hline$\varepsilon \varepsilon_{6} \cdot \Lambda$. & مليون جنيه & إجمالى تكلفه الصهر والفقد \\
\hline$\left.V_{9} V_{6}\right) \cdot r$ & مليون جنيه & ما يوازى قيمه معدن مصهور \\
\hline$\cdot 6 \cdot 1 \cdot$ & مليون جنيه & سعر الفضلات \\
\hline TOKY. & طن - ط طن & الكميه المعاد صهرها \\
\hline $70 Y_{6} Y_{\ldots}$ & مليون جنيه & إجمالى قيمه مبيعات فضلات الالومنيوم \\
\hline $1 \leq \varepsilon 69 \cdot r$ & مليون جنيه & الوفر الناتج عن إعاده التذوير \\
\hline
\end{tabular}


جمال سعد خطاب وآخرون

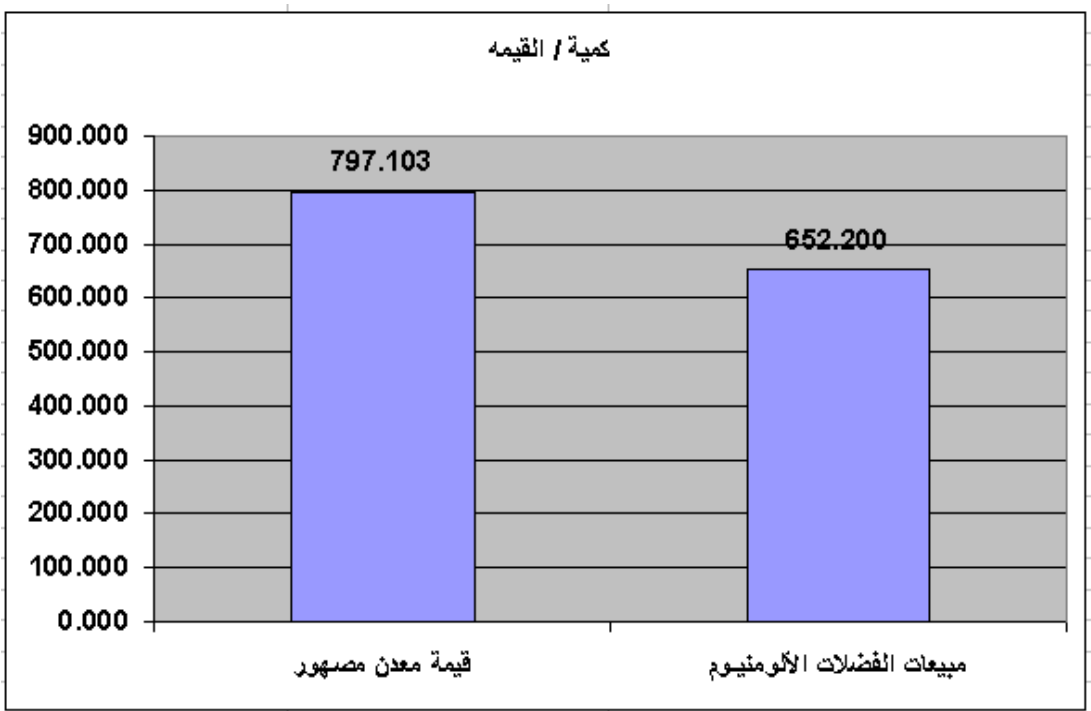

شكل(1): قيمة إعادة تدوير الالومنيوم المعيب ورايش الالومنيوم بشركة مصر للالومنيوم

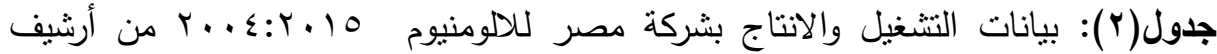
الثركه

\begin{tabular}{|c|c|c|c|c|c|c|c|c|c|}
\hline لشات & لشبركة & لكوير & لـ لكهرياء & لمعلاج "طبي & عدد المتكريتن & عدد لعالثين & تكلفة الانتاجة & لآنتاجة & لسدة \\
\hline 92904 & 325913 & 46452 & 9.1 & 46393 & 2454 & 9994 & 2213600075 & 232261 & $2005 / 2004$ \\
\hline 98760 & 675795 & 49380 & 10.1 & 45716 & 2903 & 9928 & 2461044941 & 246907 & $2006 / 2005$ \\
\hline 111916 & 800768 & 55958 & 10.9 & 46554 & 5001 & 9954 & 2893530981 & 257819 & $2007 / 2006$ \\
\hline 95058 & 906275 & 47529 & 13 & 48346 & 2513 & 9737 & 3085036355 & 256576 & $2008 / 2007$ \\
\hline 104356 & 145961 & 52178 & 20.2 & 48743 & 2272 & 9343 & 3156546678 & 248677 & $2009 / 2008$ \\
\hline 106748 & 246249 & 53374 & 20.2 & 46721 & 2342 & 9013 & 3116847060 & 267939 & $20010 / 2009$ \\
\hline 128874 & 534568 & 64437 & 23.6 & 45637 & 2284 & 9038 & 4083147466 & 303823 & $2011 / 2010$ \\
\hline 130894 & 115585 & 65447 & 26.7 & 43896 & 2114 & 9046 & 4478718071 & 307175 & $2012 / 2011$ \\
\hline 126094 & 1251 & 63047 & 30 & 42900 & 2099 & 8737 & 4725660977 & 299210 & $2013 / 2012$ \\
\hline 114050 & 263322 & 57025 & 30 & 36176 & 2609 & 8141 & 4594633631 & 306638 & $2014 / 2013$ \\
\hline 103088 & 184035 & 51544 & 38.4 & 32838 & 2474 & 7622 & 5222261182 & 297066 & $2015 / 2014$ \\
\hline
\end{tabular}




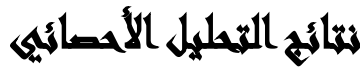

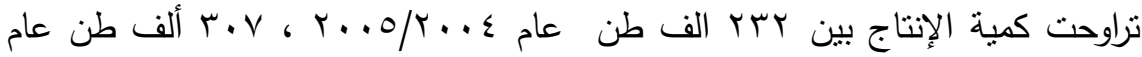

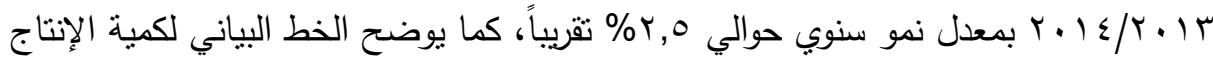
أن الإنتاج قد تذبذب بين الارتفاع والانخفاض خلال فترة الدراسة، وبلغ المتوسط الحسابي للإنتاج

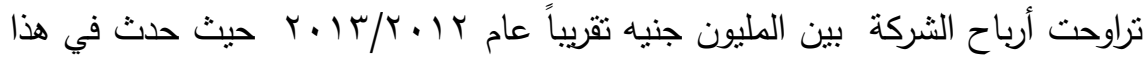

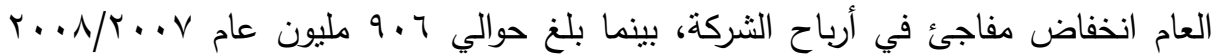
وهي طفرة حققتها الثركة في الأرباح في هذا العام، ولكن خلال الفترة الزمنية للاراسة من

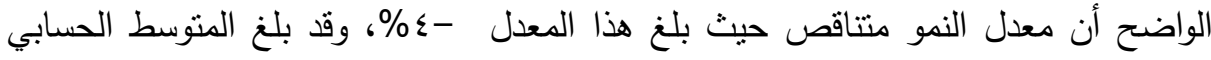
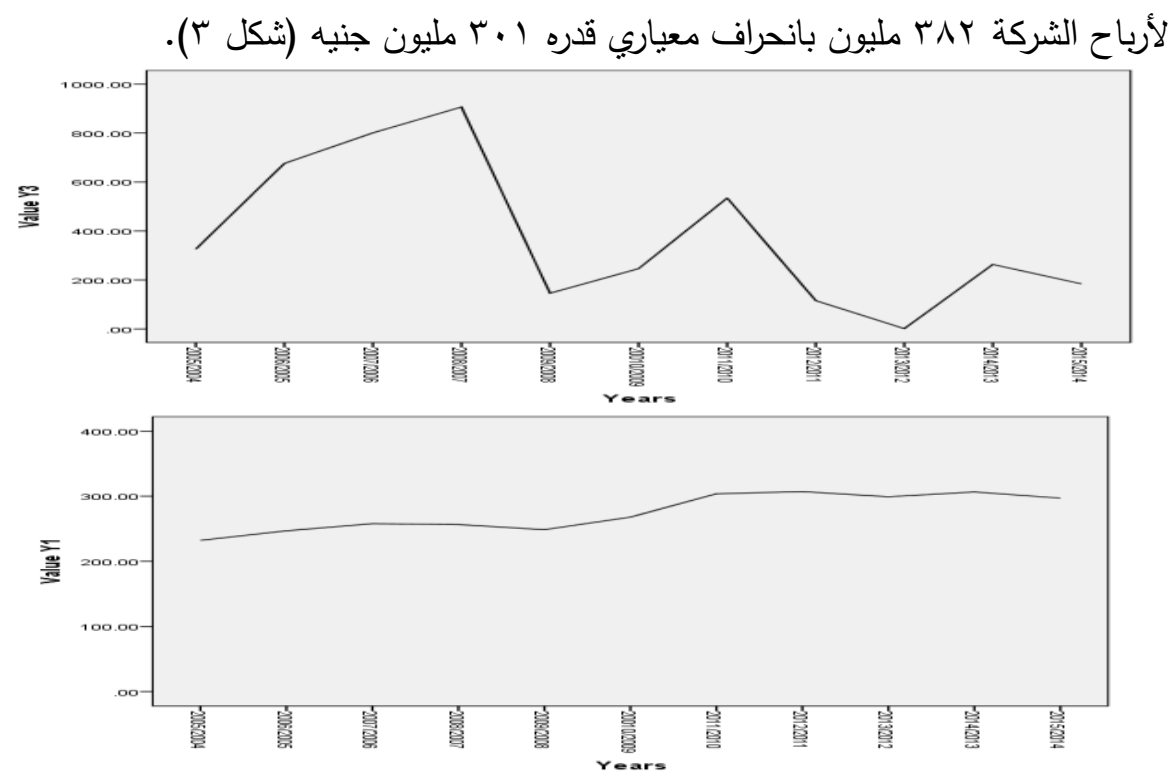

شكل(ץ): تطور كميات الإتتاج بالألف طن (اليمين) وتطور أرباح الثركة بالمليون جنيه (اليسار ) خلال فترة الدراسة 
جمال سعد خطاب وآخرون

وبإجراء الارتباط الخطي بين المتغيرات التابعة (جدول r) والمتغير المستقل (اعادة

تدوير المعدن بالطن) جاءت النتائج كما يلي: لبرنياء

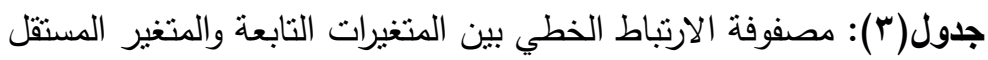

\begin{tabular}{|c|c|c|}
\hline $\bar{X}$ & & المتغيرات \\
\hline$\overline{(* *) \cdot, \wedge \cdot \varepsilon}$ & معامل الارتباط الخطي & \multirow{2}{*}{ كمية الإنتاج بالألف طن. } \\
\hline.,$\ldots r$ & مستوى المعنوية & \\
\hline (")., Trד & معامل الارتباط الخطي & \multirow{2}{*}{ قيمة الإنتاج بالمليون جنيه. } \\
\hline$\cdot, \cdot, \varepsilon$ & مستوى المعنوية & \\
\hline$\cdot, \Gamma \wedge \varepsilon-$ & معامل الارتباط الخطي & \multirow{2}{*}{ أرباح الثركة بالمليون جنيه } \\
\hline$\cdot, r \leqslant \varepsilon$ & مستوى المعنوية & \\
\hline$\cdot, 1 \leqslant \vee-$ & معامل الارتباط الخطي & \multirow{2}{*}{ عامل عدد العاملين الحاصلين على علاج طبي بالألف } \\
\hline .,747 & مستوى المعنوية & \\
\hline (")., TOY & معامل الارتباط الخطي & \multirow{2}{*}{ عدد المتدربين } \\
\hline$\cdot, \cdot r$. & مسنوى المعنوية & \\
\hline$\cdot, r \leqslant \varepsilon-$ & معامل الارتباط الخطي & \multirow{2}{*}{ عدد العاملين } \\
\hline$\cdot, r \cdot 1$ & مستوى المعنوية & \\
\hline
\end{tabular}

**. Correlation is significant at the 0.01 level (2-tailed)

*. Correlation is significant at the 0.05 level (2-tailed).

يتضح من الجدول ما يلي:

وجود علاقة ارنباط ذات دلالة معنوية موجبة قوية بين المتغير Y1 "كمية الإنتاج" والمتغير X "كمية إعادة تدوير المعدن"، حيث بلغ معامل الارتباط الخطي لبيرسون

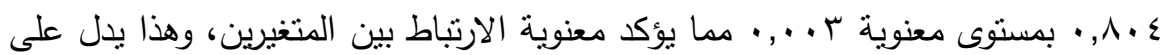
أنه يمكن إيجاد معادلة انحدار خطية لتحديد شكل العلاقة بين المتغيرين. • وجود علاقة ارتباط ذات دلالة معنوية موجبة قوية بين المتغير Y1 "قيمة الإنتاج" والمتغير X "كمية إعادة تدوير المعدن"، حيث بلغ معامل الارتباط الخطي لبيرسون

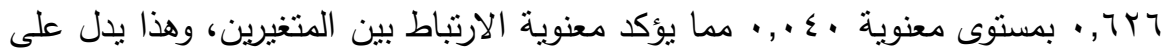
أنه يمكن إيجاد معادلة انحدار خطية لتحديد شكل العلاقة بين المتغيرين. 
• وجود علاقة ارتباط ذات دلالة معنوية سالبة قوية بين المتغير Y5 "عدد المتدربين"

والمتغير X "كمية إعادة تدوير المعدن"، حيث بلغ معامل الارتباط الخطي لبيرسون -

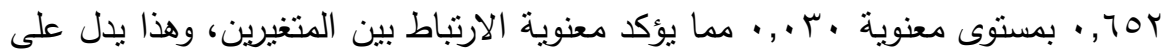
أنه بمكن إيجاد معادلة انحدار خطية لتحديد شكل العلاقة بين المتغيرين.

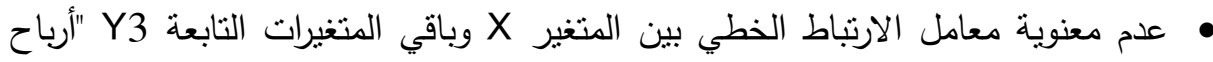
الثركة"، Y4 "عدد العاملين الحاصلين على علاج طبي"، Y6 "عدد العاملين"،، وهذا يدل على عدم وجود علاقة خطية ذات دلالة معنوية بين المتغير X وبين هذه المتغيرات، لذلك لجأ الباحث إلى البحث عن نماذج أخرى غير خطية Curve Fitting لتحديد العلاقة بين المتغير X وبين تلك المتغيرات التابعة. معادلة كمية الإنتاج: نظراً لوجود علاقة ارتباط خطية ذات دلالة معنوية كما اتضح من تحليل الارتباط السابق، فقد تم إجراء الانحدار الخطي البسيط بين المتغير X "كمية إعادة تدوير المعدن بالطن"، والمتغير Y1 "كمية الإنتاج بالألف طن" وجاءت النتائج كما يلي: جدول(؛): نتائج الانحدار البسيط بين بين المتغير X "كمية إعادة تدوير المعدن بالطن"،

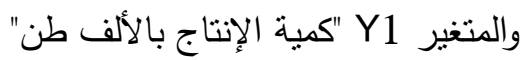

\begin{tabular}{|c|c|c|c|c|c|c|c|}
\hline \multicolumn{8}{|c|}{ المتغير المستقل: X "كمية إعادة تدوير المعدن بالطن" } \\
\hline & & & & \multicolumn{4}{|c|}{ المتغير التابع: Y1 "كمية الإنتاج بالألف طن" } \\
\hline المسنوية & 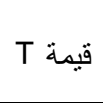 & قالمعامل & المعاملات & Sig. & $\mathrm{F}$ & $\mathrm{R}^{2}$ & $\mathrm{R}$ \\
\hline$\cdot, \cdot \wedge 4$ & 1,979 & $\wedge, q$ & ثابت الانحدار & \multirow[b]{2}{*}{$\cdot, \ldots r$} & \multirow[b]{2}{*}{$17,\{\wedge \Lambda$} & \multirow[b]{2}{*}{$\cdot, T \leqslant V$} & \multirow[b]{2}{*}{$\cdot, \wedge \cdot \vee$} \\
\hline .,. r r & $\{, \cdot 7)$ & $\cdot, \ldots r$ & الانحدار $\beta$ معامل & & & & \\
\hline
\end{tabular}




$$
\text { يتضح من الجدول ما يلي: }
$$

• معنوية النموذج ككل حيث بلغت قيمة (F=16.488) بمستوى معنوية (Sig)=0.003)

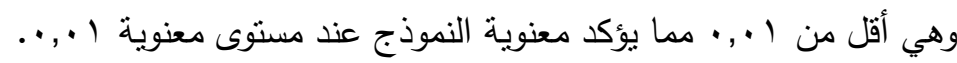

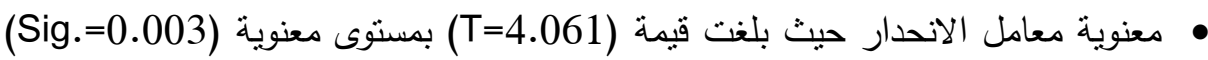

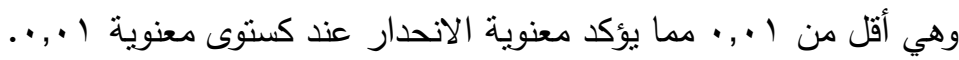
بعد تقدير معاملات النموذج يمكن صياغة النموذج بالثنكل التالي: $\mathrm{Y} 1=88.9+0.003 * \mathrm{X}+\boldsymbol{\varepsilon}$

ومن النموذج بتضح التأثثر الموجب ذو الدلالة المعنوية بين المتغير المستقل إعادة تدوير المعدن بالطن" وبين Y1 "كمية الإنتاج بالألف طن"، حيث أن زيادة كمية إعادة

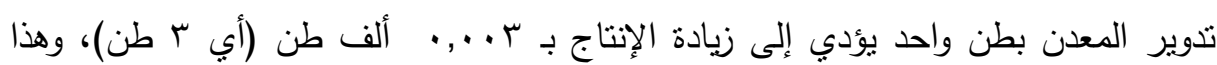

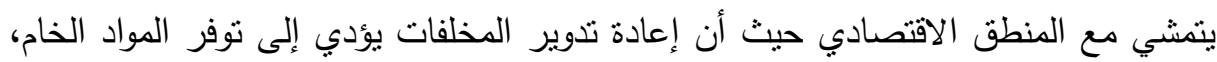

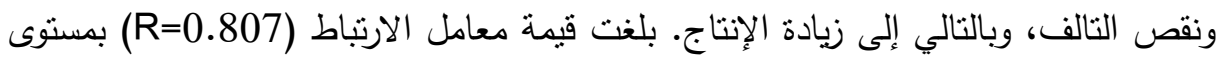

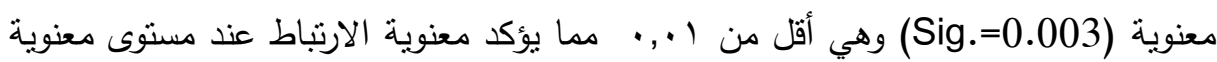
1., ، . ، كما يلغت قيمة معامل التحديد (R2=0.647) مما يعني أن المتغير المستقل يفسر

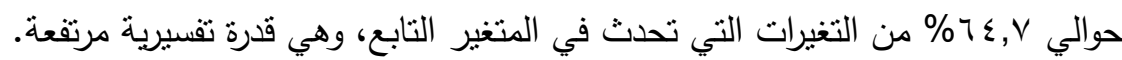

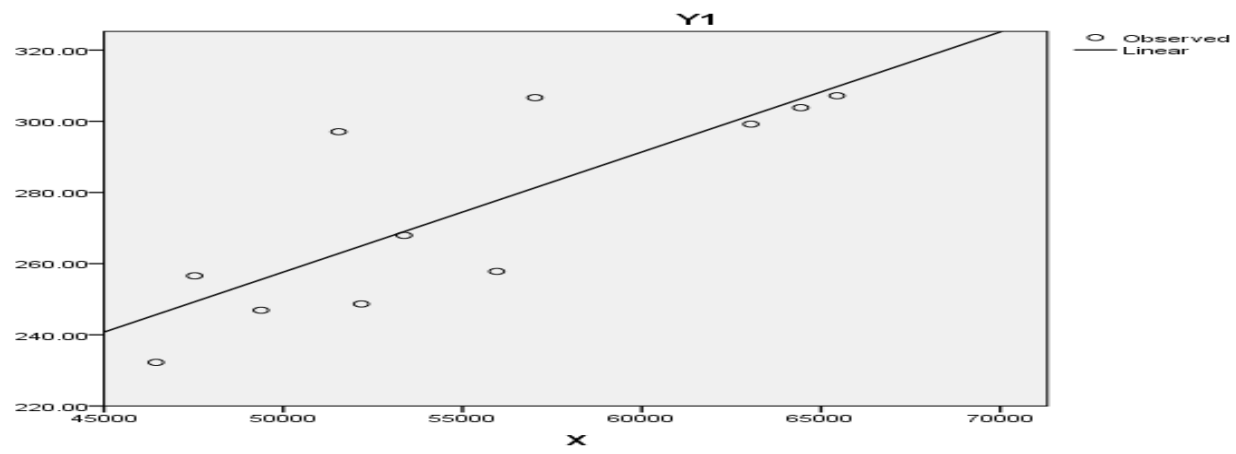

شكل (ء ): القيم المنوقعة من خط الانحدار Linear والقيم المشاهدة Observed 
يتضح من الثكل أن معظم القيم تقع قريباً من خط الانحدار Linear مما يدل على

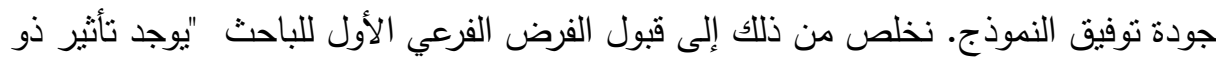

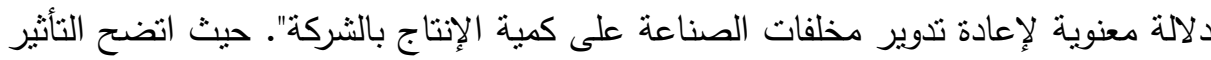
الموجب ذو الدلالة المعنوية لإعادة تدوير مخلفات الصناعة على كمية الإنتاج بالثركة.

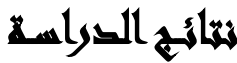

ا ـ قبول الفرض الرئيسي للباحث "يوجد تأثير ذو دلالة معنوية لإعادة تدوير مخلفات الصناعة على البيئة الاقتصادية بالثركة".

r. شركه مصر للالومنيوم شركه رائده فى إعاده تدوير مخلفات الصناعه ممايؤدى الى تقليل

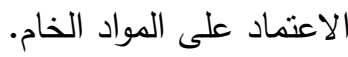

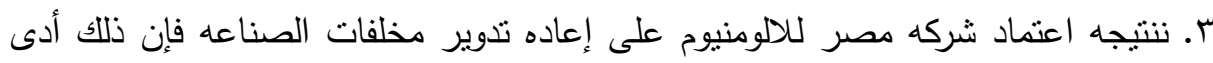
الى تخفيض التكلفه بمقدارحوالى . . . مليون جنيه. ع. إعاده التدوير لها مردود اقتصادى وبيئى حيث إن إعادة تدوير المخلفات تقلل تكلفة الإنتاج كذللك تقلل من التلوث الناتج من عملية تجميع وتتشوين هذه المخلفات

\section{تموسيايت الدراهة}

ا ـ أن تحذو الثركات الصناعيه حذو شركه مصر للالومنيوم من حيث إعاده تدوير مخلفاتها الصناعيه. r. أن تقوم الحكومه بتقديم حزمه إعفاءات ضريبيه للثركات التى تقوم بإعاده تدوير مخلفاتها بنسب متفاوته تبعاً لحجم إنتاجها مقارنهَ بحجم المواد المعاد تدويرها. r. أن ثقوم وزاره الصناعه بتدريب عمال الثركات الصناعيه ذات النشاط المتشابه على كيفيه الاستفاده القصوى من إعاده تدوير مخلفات صناعاته. 


\section{المراني}

$$
\begin{aligned}
& \text { صلاح الحجار(ع . . ץ): إداره المخلفات الصلبه البدائل - الابتكارات - الحلول ، دار الفكر }
\end{aligned}
$$

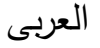

$$
\begin{aligned}
& \text { سليمان لمشعل(r ( • ץ): النفايات البيئيه الاستثمار والاقتصاد المربح، الصحيفه الالكترونيه } \\
& \text { محمد سليمان النور(9VV ( I):. حكم الاستفاده من الاوراق التالفه، مجله البحوث الفقهيه } \\
& \text { المعاصره، بالرياض العدد الثانى والثثلاثتن. } \\
& \text { محسن عبد الحميد توفيق(9AV (1)): تدوير النفايات الصناعيه فى الدول الناميه، ندوه استرجاع } \\
& \text { وتدوير النفايات الصناعيه، جهاز شئون البيئه، القاهره. } \\
& \text { محمد صابر(9^v(1): مفهوم استرداد موارد النفايات الصناعيه، ندوه استرجاع وتدوير } \\
& \text { المخلفات الصناعيه، القاهره. }
\end{aligned}
$$

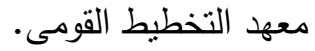

Ab Rahim S. N.; Lajis M. A. \& Ariffin S. (2015): A review on Recycling Aluminum Chips by Hot Extrusion process 12th Global Conference on Sustainable Manufacturing Procedia CIRP Volume 26761-766.

Colin A.; McMillan, Michael R.; Moore, Gregory A. Keoleian, \&Jonathan W. B. (2010): Quantifying U.S. aluminum inuse stocks and their relationship with economic output, Ecological Economics Volume 69 2606-2613

Nicks, k. (2012): Positive and negative effects of recycling. Buzzle.com.

Schlesinger E. M. (2006). Aluminum Recycling. CRC Press 284p.

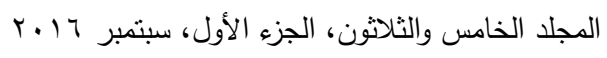


Shapely, D. (2010): Almost half of all bottled water comes from the tap, but costs you much more. The daily green. Hearst Home Design Network.

\title{
THE IMPACT OF RECYCLING WASTE INDUSTRY ON ECONOMIC ENVIRONMENT: AN EMPIRICAL STUDY ON THE ALUMINIUM COMPANY OF EGYPT
}

\author{
Khatab, G. S. ${ }^{(1)}$; Salam, S .H. ${ }^{(1)}$ and Abdel badea, A. S. ${ }^{(2)}$ \\ 1) Faculty of Commerce, Ain Shams University 2) The Aluminium \\ Company of Egypt
}

\begin{abstract}
Although the recycling of industrial wastes lead to the achievement of sustainable development through reduction of the use of raw materials from nature, as well as obliterate the waste material from the environment, a debate still exist regarding the economic value of the recycling. Therefore, we aim here to evaluate the economic aspects of the recycling in Aluminum Company of Egypt. The researchers used the quantitative analytical method for the analysis of production data and operating for the aluminium company of egypt which this data were collected in a format as a sample. this sample represents the period from 2005 to 2015 the result of statistical analysis and a positive strong correlation between recycling and the amount of company production. Moreover, recycling processes save more than 500 million pounds in addition to the provision of 130000 tons of the Alumina annually. Production of one ton aluminum requires two tons of Alumina. About 65000 tons of the industrial wastes are effectively recycled every year and therefore the disposal of these wastes decreasing the environmental hazard. Therefore, the primary research hypothesis was accepted. There is a positive economic impact of industrial wastes recycling as in case 490

$$
\text { المجلد الخامس والثلاثون، الجزء الأول، سبتمبر } 17 \text {. }
$$
\end{abstract}


جمال سعد خطاب وآخرون

of the Aluminum Company of Egypt. In addition, the environment benefits from disposal of the waste materials. Moreover, the current regulations and laws are enough for environmental conservations but it should be firmly and strictly applied.

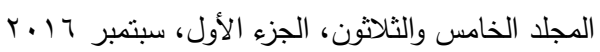

